\title{
A VET: UN ACHEGAMENTO ESTRATÉXICO PARA O DESENVOLVEMENTO ECONÓMICO, CORPORATIVO E PERSOAL NOS PAÍSES DA UE
}

PEREIRA, Orlando Petiz

Universidade do Minho, Escola de Económicas e Empresariais, Portugal

E-mail: orlandop@eeg.uminho.pt

Resumo. A Educación e Capacitación Vocacional (VET) é un proceso continuo a longo prazo de desenvolvemento económico, corporativo e persoal. Contempla a construción de competencias dinámicas para mellorar o rendemento, a produtividade e 0 desenvolvemento corporativo, persoal e social. Este artigo estuda a xeración de competencias. Enmarca a capacitación como un proceso de formación para o traballo e como a principal fonte de xeración de competencias, ao mesmo tempo que procura fomentar a creatividade. Aclara o debate con respecto á transferencia de aprendizaxe como a condición necesaria para estruturar o rendemento e a competitividade. Resalta 0 Inventario do Sistema de Transferencia de Aprendizaxe (LTSI), porque permite medir a eficacia da formación e identifica as debilidades das organizacións. Os datos usados proveñen da base de datos Eurostat.

Palabras chave: Educación, Aprendizaxe, Competencias, Formación, Sustentabilidade JEL Codes: I25, I26, J24, M53

\section{Introdución}

A formación aporta economías externas positivas aos axentes económicos. É un instrumento de cohesión e inclusión social e desenvolve un nexo de causa e efecto xunto coa proliferación das tecnoloxías. Baixo esta premisa, os cidadáns, ao exercer os seus dereitos de cidadanía, necesitan adquirir novas capacitacións e "coñecementos" para adquirir múltiples competencias. Respecto diso, a formación e a VET estanse a converter nun reto instrumental, tanto para as empresas e institucións como para os cidadáns. Por tanto, os cidadáns e as institucións necesitan asumir unha postura de aprendizaxe permanente (ao longo das súas vidas) co obxecto de superar retos cotiáns para contribuír á sustentabilidade das organizacións e para mellorar os índices de cohesión social.

Este concepto, tamén defendido por Landriscini et al. (2006/07), baséase na premisa de que o coñecemento xera máis coñecementos prácticos en lugar de coñecementos "de enunciados", xa que o coñecemento xera máis coñecemento e se aprende sobre todo mediante a observación, a imitación e a auscultación (Pereira, 2013a; 2013b). Estrutúrase mediante o concepto da aprendizaxe práctica, onde a formación é unha estratexia variable. Tamén é relevante para a cohesión social e o rendemento nacional mediante o seu impacto na economía. Daí o esforzo, a miúdo ao nivel de inflación lexislativa, que se realizou na área da formación e a aprendizaxe permanente, tanto no ámbito rexional como máis amplo, como pode ser o da Unión Europea. De feito, a lei portuguesa en particular, no seu artigo 3 do decreto lei 396/ 2007 do 31 de decembro, non distingue entre os conceptos de educación e formación e os dous aparecen baixo a mesma definición. A educación e a formación son instrumentos importantes para actualizar e espallar o coñecemento. Queremos profundar na educación e formación como instrumentos de aprendizaxe organizativa e individual. Neste senso, discorremos na necesidade de cambios no comportamento corporativo para mellorar a resposta á volatilidade dos mercados. A nosa análise pon énfase no modelo do Inventario do Sistema de Transferencia de Aprendizaxe (LTSI), que procura medir a eficacia da formación. Tamén identifica as fraquezas das organizacións para as que se poden deseñar solucións co obxecto de mellorar as condicións e, por tanto, facer que as organizacións sexan aínda máis sostibles, ademais de argallar novos proxectos para a vida persoal e social. 
$\mathrm{O}$ artigo divídese en catro seccións. A segunda amosa un marco teórico para as competencias formativas e organizativas. Esta sección elabora os conceptos das perspectivas exploratorias e utilitarias. A perspectiva exploratoria desprégase como un proceso de aprendizaxe para procurar e explorar, mentres que a perspectiva utilitaria avoga por comportamentos máis pasivos e prioriza as solucións a curto prazo. Tamén expón a formación como un proceso alternado, tamén chamado educación de segunda oportunidade. É unha perspectiva dinámica de produción de competencias porque asocia as nocións de capacitación, mobilidade, capacidade de emprego e competitividade, unindo as contribucións da educación e o mercado de traballo. Na sección tres, procuramos relacionar a formación cos modelos do Inventario do Sistema de Transferencia de Aprendizaxe. Trátase dun modelo holístico que identifica factores que fomentan a transferencia da aprendizaxe nun contexto corporativo. Este modelo baséase nos fundamentos das organizacións de aprendizaxe, onde o know-how convértese na referencia para a transferencia de coñecemento e a produción de novas dinámicas e competencias. Na sección catro presentamos os datos para os países, concretamente os europeos, para o período 2005 a 2014. Os datos aportan información sobre o nivel de implicación das persoas con escasa formación na aprendizaxe permanente, e tamén sobre a implicación das empresas na formación. Finalmente, presentamos os nosos achados e as razóns para continuar estimulando a formación. A formación considérase unha variable estratéxica para o desenvolvemento persoal, corporativo e rexional, que precede á presentación de anexos que amosan datos por xénero sobre a implicación de adultos na formación permanente.

\section{Marco teórico}

\subsection{Da formación ás competencias organizativas}

A meirande parte das definicións de educación e formación refírense ao concepto de competencias. Este é o exemplo da actual lexislación en Portugal, onde o artigo 3 do decreto-lei 396/2007 define as competencias como a "capacidade recoñecida para mobilizar os coñecementos, as aptitudes e as actitudes en contextos de traballo, de desenvolvemento profesional, de educación e de desenvolvemento persoal". É un concepto xeral e adquire diferentes significados segundo diferentes contextos (Descy e Tessaring, 2001). Produce un coñecemento flexible, adaptable e transferible, que figura como requerido polos actores económicos que operan nos mercados actuais (Greenam et al., 1997). Por tanto, é importante implantar unha cultura organizativa de aprendizaxe continua, que se estende a todos. Porén, as organizacións que adoptan esta cultura debe asumir a actitude do alumno e non só a actitude do avaliador. De feito, o primeiro é vocacional a longo prazo e oriéntase á eficacia, mentres que o segundo funciona a curto prazo e está centrado na eficacia dos resultados.

En xeral, e tamén en termos específicos, a formación sempre foi a principal fonte de produción de aptitudes e competencias (Pereira, 2008; 2013a; 2013b). Promove os talentos e estimula a creatividade e a responsabilidade dos colaboradores en función do seu rendemento. Pero a produción de novo coñecemento é o resultado de procesos interactivos, dinámicos, sistémicos, integrados e multidimensionais. Estas son dimensións que profundaron a consciencia dos axentes económicos con respecto aos procesos de aprendizaxe (Nelson e Winter, 1982; Cohen e Levinthal, 1990). Este achegamento tamén representou con máis coherencia que nunca as capacidades innovadoras das empresas (Lundvall, 1985 e 1988; Rosemberg, 1986) e levou ao desenvolvemento e mellora das teorías de aprendizaxe nas organizacións. Pero, dada a actual revolución da información, a innovación non descansa sobre perspectivas lineais ou características de capacidade de predición dos resultados, daí a necesidade de accións que combinen unha perspectiva 
integrada, multidimensional, sistémica e interactiva (Lundvall, 1988). Por iso semella obrigatorio concentrarse na formación e aprendizaxe organizativa dende a perspectiva exploratoria e menos na utilitaria (March, 2006), porque a exploratoria se traduce nunha especie de "procura" de aprendizaxe, é dicir, fomenta o descubrimento e aplicación de novos conceptos e procedementos corporativos. Pola súa parte, a perspectiva utilitaria concéntrase no que existe, é dicir, trata de introducir melloras no comportamento corporativo. Avoga por un procedemento máis prudente, condicionando resultados pasivos con obxectivos a curto prazo. Estes resultados son acumulativos pola súa propia natureza, do mesmo modo que as innovacións que acadan. Pola contra, a perspectiva exploratoria é máis provocadora, estimulante e astuta porque se atreve a procurar algo "novo". O seu comportamento implica algo de ruptura.

A formación permite ás persoas renovar as súas aptitudes iniciais (Bishop, 1998; Nisar, 2004; Pereira, 1997; Pereira, 2001). É un proceso de adquisición de competencias, conceptos, regras e actitudes co obxectivo último de mellorar o rendemento da organización (Byars e Rue, 1996). É un investimento estratéxico ao que deberían recorrer as organizacións cando desexen aportar competencias dinámicas aos seus traballadores. Este concepto subliña a teoría do capital humano, mediante o cal as organizacións participan activamente na elevación da súa excelencia. Úsase como proxy do coñecemento e compentencias en economía (Comisión Europea, 2015; Bilhim, 2006). Procura ofrecer aos empresarios un maior grao de flexibilidade, creatividade, capacidade de adaptación e toma de decisións (Cedefop, 2014; Comisión Europea, 2015; Walker, 1987), e, ao mesmo tempo, achégalles unha gama de ferramentas e técnicas para que a empresa sexa máis competitiva no mercado de traballo (Cruz, 1998).

A pesar das posibilidades de formación, os seus obxectivos son polémicos abondo, como é o caso dos esforzos realizados por institucións como a Organización Internacional do Traballo (ILO). Conforme á ILO, a formación é un proceso no que as persoas melloran mediante coñecemento e competencias novas, o cal vai moito máis aló do coñecemento técnico e instrumental. Este concepto xa identificou unha rede de coñecementos transversais a diferentes áreas, como no caso de cuestións relacionais, emocionais e de comportamento (Pereira, 2008). É neste senso que Lundvall (2006) considera que a xestión das competencias dos empresarios é unha referencia de rendemento económico. $\mathrm{O}$ autor engade que estas competencias débense combinar coas competencias organizativas e considera que, en lugar de posuír estas compentencias, hai que saber como usalas. Por tanto, opina que máis que adquirir competencias, convén aferrarse a aquelas que crean e estimulen un ambiente de aprendizaxe e interacción. Neste senso, habería que adquirir capacidades tecnolóxicas dinámicas de amplo espectro que, conforme a Lall (1992), combinen as competencias e aptitudes para adquirir, usar, adaptar, mellorar, crear e diseminar as novas tecnoloxías. Non se poden importar, senón que se deben adaptar ás situacións (Le Clech e Gimenez, 2015). É un concepto completo que inclúe as capacidades de innovación e absorción (Cohen e Levinthal, 1990; Lugones e Gutti, 2006). Non se pode negar que a formación opera ao nivel do desenvolvemento do pensamento crítico. Axuda ao individuo a ser máis autónomo, responsable e sensible. Mobiliza o coñecemento, acelera a resolución de problemas cotiáns e fai que as persoas se convertan en elementos activos no contexto do proceso corporativo de aprendizaxe. Este concepto está apoiado por Thang et al., (2010) que consideran que, para acadar os seus obxectivos, as organizacións deben contar con traballadores que teñan coñecementos, aptitudes, competencias, comportamentos e actitudes, todo o que se considera condicións de emprego e desempeño (Contreras Cueva et al., 2014).

\subsection{VET: a educación de segunda oportunidade}


A educación para adultos consíderase estratéxica en toda a Unión Europea (Cedefop, 2008; Comisión Europea, 2015). As institucións europeas usan expresións equivalentes, como, por exemplo, "capacitación", "apitudes básicas", "educación básica para adultos" e "educación de segunda oportunidade". As aptitudes básicas, competencias básicas ou competencias chave son aptitudes aplicables ao mercado de traballo e tamén ás vidas cotiáns dos cidadáns. Trátanse de aptitudes para usar, aplicar e interpretar información co obxecto de resolver problemas, especialmente en contornas máis intensivas en tecnoloxía (Cedefop, 2008). Porén, en xeral, son conceptos dirixidos máis ben a adultos, dándolles unha segunda oportunidade de aprendizaxe. Pero, a propósito de segundas oportunidades, particularmente ao nivel de competencias básicas, a VET (educación e capacitación vocacional) debería ser considerada. Por tanto, facilita o proceso de aprendizaxe para adultos que teñen un nivel baixo de formación e aptitudes. 0 seu proceso de aprendizaxe é dirixido, flexible e axustado ás características de alumnos adultos. Como recomenda a Comisión Europea (2015), a flexibilidade é a chave o exito do chamado proceso de "educación de segunda oportunidade". Ao mesmo tempo, o cumprimento das recomendacións da VET permite evitar posibles conflitos que poidan xurdir entre a formación e o traballo, así como entre a formación e a familia. Neste senso, a VET defínese como actividades organizadas e estruturadas que pretenden ofrecer ás persoas o coñecemento, aptitudes e competencias necesarias para realizar un traballo ou un conxunto de traballos ou para determinadas profesións (Cedefop, 2014: 6)

Segundo Calleja (Cedefop, 2014), a contribución da VET para a competitividade económica está moi subestimada. De feito, o desenvolvemento das competencias comezan co sistema educativo, para logo seguir co compromiso da persoa ao longo da súa vida adulta, combinando a educación e a formación coa aprendizaxe no lugar de traballo. En realidade, o primeiro ciclo de educación apórtalle ás persoas o primeiro nivel de cualificacións, que se desenvolven e refinan na vida adulta. Esta perspectiva considera que as competencias non se desenvolven por separado (Gómez, Tobarra e López, 2014), senón que outras aportacións tamén xogan un papel significativo en todo o proceso, porque a meirande parte dos empresarios axudan aos menos cualificados (Kirby e Riley, 2008), tanto no desempeño das súas funcións como na mellora das súas competencias.

A realidade revela que as cualificacións se poden obter non só mediante a educación xeral, senón a través da VET. A que se obtén mediante a VET considérase máis robusta e dirixida a obxectivos a curto prazo. Pero, hai unha gran diversidade de tipoloxías de VET. A contorna macroeconómica afecta o seu deseño, do mesmo xeito que outras áreas como a política, cultural, social e legal.

A axenda europea para a educación e formación para adultos leva dende 2011 renovándose. O seu principal referente é, sen dúbida, a aprendizaxe alternativa para adultos con baixo nivel de aptitudes e cualificacións.

Porén, dende mediados dos anos 90 aumenta a preocupación con respecto a este tema, con recomendacións para a aprendizaxe permanente en diversas áreas e externa ao sistema educativo ortodoxo, incluíndo o emprego, benestar, saúde, traballo voluntario e comunitario, innovación, mocidade, inmigración, desenvolvemento rexional e outros (Comisión Europea, 2015: 35). Como defende a UNESCO, a Comisión Europea (2015:43) aclara a súa preocupación pola alfabetización e aptitudes básicas para adultos e define a súa habilidade de identificar, entender, interpretar, crear, comunicar e contar, usando materiais impresos e escritos asociados a unha variedade de contextos. Estes son esforzos para reintroducir ás persoas no mercado de traballo con eficacia. Isto é unha guía para a formación dirixida ao traballo, o cal é un modo de formación que responde eficientemente ás necesidades das empresas. Neste contexto, a formación inclúe os coñecementos de 
como facer, como existir e como ser, o cal coincide coas recomendacións realizadas polo Consello Europeo en marzo de 2000, cuxo obxectivo estratéxico era transformar a Unión Europea nunha economía baseada no coñecemento para que sexa a máis dinámica do mundo. Neste senso, debería promover a inclusión e cohesión social, a mobilidade, a capacidade para atopar emprego e a competitividade (Wollschläger, 2004) e ter múltiples aptitudes (Pereira, 1997). Este concepto de amplo espectro explica a razón pola que algunhas empresas están preparadas para investir na VET permanente, e, por tanto, desenvolven unha cultura organizativa de aprendizaxe. En efecto, a formación profesional é importante, dadas as economías externas positivas que afectan aos actores económicos, e, ademais, é unha variable consoante cos novos valores de recursos intanxibles.

\section{Modelos do Inventario de Sistemas de Formación e Transferencia da Aprendizaxe}

Debido á revolución da información, o individuo xa non é "clasificado" pola función e/ ou traballo que desempeña. Hoxe en día, os individuos son apreciados pola súa habilidade de acumular coñecemento e capacidade para resolver problemas. Isto vai unido ao cambio social e cambios provocados pola oscilación dos sistemas económicos e que están transformando o Estado-Nación en Estado global/ local (Magalhães e Stoer, 2006). Por tanto, os trababallores deberían formarse en varias competencias, dende a versatilidade, a flexibilidade, a creatividade e o autocontrol ata as de tipo interpersoal, relacional, comunicativa, emocional e ética (Pereira et al., 2007; Pereira, 2008). Neste acelerado proceso de cambio, as economías de aprendizaxe teñen unha resposta positiva. É un dos modelos máis relevantes e modernos. Deste modo, a nova economía require altos niveis de educación e cognición, o que explica porque Lundvall (2007) considera que a educación superior debería prestarlle especial atención ás capacidades dos alumnos. Neste proceso de aprendizaxe colectivo, a produción de modelos que avalíen a eficacia e eficiencia da transferencia de aprendizaxe desempeña un papel de máxima importancia porque esta transferencia controla e valida o sistema de formación. Dende ese punto de vista, Afonso (2000) considera que a avaliación é unha ferramenta de xestión esencial en toda organización e que adquire unha relevancia maior na estruturación de relacións de traballo. Tamén é un importante instrumento de control e lexitimidade organizativa. Neste contexto, xorde o Modelo de Holton (Holton et al., 2000), o chamado Inventario de Sistemas de Transferencia da Aprendizaxe (LTSI). Foi deseñado para identificar factores que promoveran a transferencia de aprendizaxes no contexto corporativo, malia que con base no desempeño individual (Holton et al., 2007). Isto explica o motivo polo que se lle chama "sistema de transferencia", poñendo énfase nos factores máis amplos e inherentes ao individuo, á formación e á organización, todos eles susceptibles de exercer unha influencia sobre a transferencias de aprendizaxe ao desempeño de funcións (Holton et al., 2000), como se amosa na Figura 1 do Anexo.

Esta ferramenta considera a existencia de dezaseis factores agrupados en catro escalas: (i) a capacidade de usar con eficacia o coñecemento e a experiencia; (ii) a motivación para usar o coñecemento e a experiencia; (iii) a contorna no lugar de traballo deseñado para fomentar a aplicación do coñecemento e da experiencia; e (iv) as características do aprendiz (Donovan et al., 2001). O modelo tende a unha aproximación entre os construtos da aprendizaxe organizativa e individual. Donovan et al. (2001) considérano un modelo holístico debido á intensidade das relacións que desenvolve. Pero, a aprendizaxe organizativa non depende só da aprendizaxe individual, senón tamén das dinámicas que existan na organización. Depende da contorna contextual, motivo polo que Pereira (1997) considérana a forma máis sublime de subsidio do Estado para a cidadanía. Porén, como os individuos aprenden observando o comportamento de outros e 
reflexionando sobre o seu propio comportamento (Fernandes, 2007), a aprendizaxe organizativa tamén ten unha influencia das áreas cognitivas individuais e da súa habilidade para asimilar e transferir esa cognición individual. De feito, a aprendizaxe baseada na experiencia beneficia a formación técnica dos traballadores. Por tanto, necesitamos institucionalizar a análise da acción despois de que sexa realizada, a posteriori. Neste senso, a institucionalización do fracaso e dos erros constitúen reveses no curso da aprendizaxe, e é esencial para promover a implantación da cultura de aprendizaxe e para estruturar o seu proceso evolutivo. Neste contexto, é importante realizar unha avaliación da aprendizaxe sen perder de vista o feito de que aprender permite transformar o coñecemento tácito en coñecemento codificado (Nonaka, 1991) e facelo dispoñible para a comoditización (Pereira, 2001).

Conforme a Holton et al. (2000), e o seu modelo (LTSI), ademais de acelerar o proceso de transferencia da aprendizaxe, permite realizar un perfil da organización e das súas prácticas. Semella que a súa referencia vai máis aló disto e tamén permite a xestión do coñecemento corporativo, a construción de mapas de coñecemento para a organización e redefinir e instituír novas rutinas corporativas, que son determinantes para o éxito da transferencia de aprendizaxe e o rendemento e para o éxito da organización máis xeral (Pereira et al., 2007). Por tanto, a implantación do Modelo de Holton implica a verificación das precondicións dentro e fóra da compañía, mentres que se fundamenta na aprendizaxe permanente e na educación para adultos e os procesos educativos, alternativamente, para consolidar o "know-know" co know-how. Por outra banda, o Modelo de Holton encarna características de inclusión e satisfacción co posto de traballo, e pódese usar como un instrumento para reducir as asimetrías existentes entre a poboación e as rexións. Porén, é un modelo deseñado para as organizacións, dentro das que os esforzos se deben realizar co obxectivo de motivar a aprendizaxe, o coñecemento e a súa transferencia.

\section{- A análise en cifras}

Este estudo utiliza datos presentados dende unha perspectiva macro, porque a formación permanente inclúe todas as actividades de aprendizaxe, tanto se a aprendizaxe se atopa inserida no sistema educativo formal como no non formal ou informal. Por tanto, os datos aquí presentados son agregados e non fan distinción con respecto ao tipo ou características da aprendizaxe, empresas, traballadores, industria ou as súas fontes de financiamento, divididos por todos os actores económicos implicados. Así que, tendo en conta o deseño dos datos, xa non podemos analizar os beneficios da formación e non podemos presentar a tipoloxía dos traballadores implicados na formación permanente, clasificados en función dos seus obxectivos e motivacións, grupos de idade, niveis educativos e xénero. Tampouco deixa que o estudo presente a tipoloxía das empresas implicadas, clasificadas por sectores de actividade, dimensión e densidade do tecido humano. De feito, a aprendizaxe permanente inclúe unha serie de inciativas formativas, independentemente do seu tipo, obxectivos, duración e fontes de financiamento. Algunhas delas son más específicas e xenéricas, dende a alfabetización de adultos, formación básica fóra dos colexios, aptitudes xerais para a vida e o traballo, habilidades sociais, compentencias para o desenvolvemento persoal e educativo, ata outras áreas de formación como a emocional, a espiritual, a relacional, ou compentencias éticas e de cidadanía, entre outras. Por tanto, os datos de formación presentados inclúen a persoas con idades entre 25 e 64 anos. A recolleita de datos vén de varias fontes, como poden ser a enquisa á man de obra e formación para adultos realizada pola UE e os países da AELC. As enquisas utilizadas eran estándares e incluían todas as actividades da educación e aprendizaxe permanente, dende os aspectos formais da formación non formal ou informal, ata actividades relativas ao traballo. 
Segundo Cedefop (2013), os beneficios xerados pola educación e a formación agrúpanse entre beneficios de mercado e beneficios que non son de mercado, que producen economías externas positivas para a sociedade, as empresas e os cidadáns. Os beneficios de mercado son: (i) crecemento económico, (ii) resultados no mercado laboral, (iii) rendemento da empresa, (iv) produtividade do traballador, (v) emprego, (vi) ganancias, (vii) estatus e desenvolvemento de carreiras profesionais. Por outra banda, os resultados que non son de mercado destacan polos seguintes factores: (i) redución do crime, (ii) cohesión social, (iii) saúde, (iv) solidariedade interxeracional, (v) inclusión de minorías ou grupos desvataxados, (vi) satisfacción coa vida (sentimento de realización) e (vii) motivación individual. Fronte a estes beneficios, semella clara a necesidade de insistir avanzando no mercado binomial da educación/mercado de traballo, dados os seus numerosos efectos positivos no benestar da humanidade, nos salarios, capacidade de emprego, entre outros (Gómez, Tobarra e López, 2014). Porén, en Europa, as persoas na franxa de idade entre os 25 e os 64 anos con cualificacións baixas teñen menor probabilidade de participar da educación para adultos, cuxa cifra media atópase estancada nun 3,8\% tal e como amosa a Táboa 1.

Os datos revelan comportamentos e sensibilidades diferentes con respecto á formación permanente. A meirande parte dos países amosan debilidades para implicar aos adultos na formación. Por unha banda, os países nórdicos (Suecia, Noruega, Finlandia, Islandia, Suiza, Dinamarca e o Reino Unido) revelan un maior grao de sensibilidade neste tema. Tamén hai evidencia dunha implicación das persas na aprendizaxe permanente segundo o xénero (véxanse os Anexos A e B), porque a formación permanente tamén é unha variable de inclusión social. Neste senso, cabe destacar que os países nórdicos implican de forma moi significativa ás mulleres na formación permanente. Destacan Dinamarca e Suecia xa que revelan unha porcentaxe de implicación das mulleres que chega ao $37,0 \%$ e $35,6 \%$ respectivamente, comparado co $25,8 \%$ e $21,9 \%$ para os homes no ano 2014.

Table 1: Aprendizaxe permanente, 2005 -2014 (\% da poboación con idades entre 25 e 64 anos que participa na educación e formación)

\begin{tabular}{l|llllllllll} 
Lugar/Ano & 2005 & 2006 & 2007 & 2008 & 2009 & 2010 & 2011 & 2012 & 2013 & 2014 \\
\hline Turquía & $:$ & 1,8 & 1,5 & 1,9 & 2,3 & 2,5 & 2,9 & 3,2 & 4,0 & 4,8 \\
Bulgaria & 1,3 & 1,3 & 1,3 & 1,4 & 1,4 & 1,2 & 1,3 & 1,5 & 1,7 & 1,7 \\
Romanía & 1,6 & 1,3 & 1,3 & 1,5 & 1,5 & 1,3 & 1,6 & 1,4 & 2,0 & 1,7 \\
Grecia & 1,9 & 2,0 & 2,2 & 3,0 & 3,3 & 3,1 & 2,5 & 3,0 & 3,0 & 3,0 \\
Croacia & 2,1 & 2,9 & 2,4 & 2,2 & 2,3 & 2,2 & 2,3 & 2,4 & 2,9 & 2,5 \\
Hungría & 3,9 & 3,8 & 3,6 & 3,1 & 2,7 & 2,8 & 2,7 & 2,8 & 3,0 & 3,3 \\
Portugal & 4,1 & 4,2 & 4,4 & 5,3 & 6,4 & 5,7 & 11,5 & 10,5 & 9,7 & 9,7 \\
Eslovaquia & 4,6 & 4,1 & 3,9 & 3,3 & 2,8 & 2,8 & 3,9 & 3,1 & 2,9 & 2,9 \\
Polonia & 4,9 & 4,7 & 5,1 & 4,7 & 4,7 & 5,2 & 4,4 & 4,5 & 4,3 & 4,1 \\
Malta & 5,2 & 5,5 & 5,9 & 6,2 & 6,1 & 6,0 & 6,4 & 6,9 & 7,6 & 7,5 \\
República Checa & 5,6 & 5,6 & 5,7 & 7,8 & 6,8 & 7,5 & 11,4 & 10,8 & 9,7 & 9,4
\end{tabular}




\begin{tabular}{l|llllllllll} 
Italia & 5,8 & 6,1 & 6,2 & 6,3 & 6,0 & 6,2 & 5,7 & 6,6 & 6,2 & 7,6 \\
Francia & 5,9 & 6,4 & 6,1 & 6,0 & 5,7 & 5,0 & 5,5 & 5,7 & 17,7 & $:$ \\
Chipre & 5,9 & 7,1 & 8,4 & 8,5 & 7,8 & 7,7 & 7,5 & 7,4 & 6,9 & 7,0 \\
Estonia & 6,0 & 6,5 & 7,0 & 9,7 & 10,5 & 10,9 & 11,9 & 12,7 & 12,6 & 12,3 \\
Lituania & 6,1 & 4,7 & 5,2 & 4,8 & 4,4 & 3,9 & 5,7 & 5,2 & 5,7 & 5,2 \\
Irlanda & 7,4 & 7,3 & 7,6 & 7,0 & 6,3 & 6,8 & 6,8 & 7,1 & 7,3 & 6,9 \\
Alemaña & 7,7 & 7,5 & 7,8 & 7,9 & 7,8 & 7,7 & 7,8 & 7,9 & 7,8 & 7,9 \\
Latvia & 7,8 & 6,8 & 6,9 & 6,6 & 5,4 & 5,1 & 5,1 & 6,9 & 6,5 & 5,9 \\
Bélxica & 8,3 & 7,5 & 7,2 & 6,8 & 6,8 & 7,2 & 7,1 & 6,6 & 6,7 & 7,2 \\
Luxemburgo & 8,5 & 8,2 & 7,0 & 8,5 & 13,4 & 13,4 & 13,6 & 13,9 & 14,4 & 13,8 \\
España & 10,8 & 10,6 & 10,6 & 10,6 & 10,6 & 11,0 & 11,0 & 11,0 & 11,1 & 10,1 \\
Austria & 12,9 & 13,1 & 12,8 & 13,2 & 13,8 & 13,7 & 13,4 & 14,1 & 13,9 & 14,2 \\
Eslovenia & 15,3 & 15,0 & 14,8 & 13,9 & 14,6 & 16,2 & 15,9 & 13,8 & 12,4 & 12,2 \\
Países Baixos & 15,9 & 15,6 & 16,6 & 17,0 & 17,0 & 16,6 & 16,7 & 16,5 & 17,4 & 17,7 \\
Suecia & 17,4 & 18,4 & 18,6 & 22,2 & 22,2 & 24,4 & 24,9 & 26,7 & 28,1 & 28,6 \\
Noruega & 17,8 & 18,7 & 18,0 & 19,3 & 18,1 & 17,8 & 18,2 & 20,0 & 20,4 & 19,7 \\
Finlandia & 22,5 & 23,1 & 23,4 & 23,1 & 22,1 & 23,0 & 23,8 & 24,5 & 24,9 & 25,0 \\
Islandia & 25,7 & 27,9 & 27,0 & 25,1 & 25,1 & 25,2 & 25,9 & 27,3 & 25,8 & 26,4 \\
Suiza & 27,0 & 22,5 & 26,8 & 27,9 & 23,9 & 30,6 & 29,9 & 29,9 & 30,4 & 31,2 \\
Dinamarca & 27,4 & 29,2 & 29,0 & 29,9 & 31,2 & 32,5 & 32,3 & 31,6 & 31,4 & 31,4 \\
Reino Unido & 27,6 & 26,7 & 20,0 & 19,9 & 20,1 & 19,4 & 15,8 & 15,8 & 16,1 & 15,9
\end{tabular}

: non dispoñible. http:// appsso.eurostat.ec.europa.eu/ nui/ submitViewTableAction.do 02/ 04/ 2015)

Considerando a evidencia e, sobre a base dos supostos económicos teóricos, deberíamos poñer máis énfase na formación dos adultos porque estrutura a sociedade no seu conxunto. De non o facer, a cohesión social, xustiza/ equidade, os dereitos da cidadanía e os grupos social vulnerables continuarán aumentando, producindo unha división no desenvolvemento dos países, rexións e persoas, que non axuda ao desenvolvemento harmónico e concéntrico de Europa, nin respecta ás intencións dunha "Europa máis inclusiva”. Porén, a implicación das empresas na formación é baixa (véxase a Táboa 2), e iso non axuda aos traballadores a implicarse na actualización dos seus coñecementos. 
Táboa 2: Empresas con formación en \% de traballadores, por clase de tamaño

\begin{tabular}{|c|c|c|c|c|c|c|c|c|}
\hline Clase de & \multicolumn{2}{|l|}{ Total } & \multicolumn{2}{|c|}{ [10-49] } & \multicolumn{2}{|c|}{ [50-250] } & \multicolumn{2}{|l|}{$>250$} \\
\hline Lugar/Ano & 2005 & $\begin{array}{l}201 \\
0\end{array}$ & 2005 & $\begin{array}{l}201 \\
0\end{array}$ & 2005 & 2010 & 2005 & 2010 \\
\hline Bélxica & 63 & 78 & 58 & 74 & 86 & 94 & 99 & 99 \\
\hline Bulgaria & 29 & 31 & 24 & 27 & 44 & 49 & 61 & 80 \\
\hline $\begin{array}{l}\text { República } \\
\text { Checa }\end{array}$ & 72 & 72 & 66 & 68 & 93 & 90 & 100 & 97 \\
\hline Dinamarca & 85 & 91 & 83 & 89 & 96 & 98 & 99 & 100 \\
\hline Alemaña & 69 & 73 & 65 & 69 & 81 & 82 & 87 & 96 \\
\hline Estonia & 67 & 68 & 62 & 64 & 85 & 83 & 96 & 97 \\
\hline Irlanda & 67 & $:$ & 61 & : & 86 & : & 100 & : \\
\hline Grecia & 21 & 28 & 16 & 24 & 39 & 46 & 70 & 83 \\
\hline España & 47 & 75 & 43 & 72 & 68 & 90 & 89 & 97 \\
\hline Francia & 74 & 76 & 69 & 72 & 98 & 95 & 100 & 98 \\
\hline Croacia & : & 57 & $:$ & 53 & $:$ & 73 & $:$ & 86 \\
\hline Italia & 32 & 56 & 29 & 53 & 58 & 77 & 86 & 91 \\
\hline Chipre & 51 & 72 & 45 & 68 & 80 & 88 & 100 & 100 \\
\hline Latvia & 36 & 40 & 31 & 37 & 56 & 54 & 76 & 82 \\
\hline Lituania & 46 & 52 & 40 & 48 & 64 & 67 & 88 & 89 \\
\hline Luxemburgo & 72 & 71 & 68 & 66 & 85 & 86 & 95 & 100 \\
\hline Hungría & 49 & 49 & 42 & 43 & 77 & 74 & 90 & 95 \\
\hline Malta & 46 & 54 & 40 & 49 & 65 & 73 & 87 & 90 \\
\hline Países Baixos & 75 & 79 & 71 & 75 & 88 & 89 & 96 & 97 \\
\hline Austria & 81 & 87 & 79 & 85 & 91 & 96 & 99 & 99 \\
\hline Polonia & 35 & 22 & 27 & 16 & 55 & 41 & 80 & 75 \\
\hline Portugal & 44 & 65 & 39 & 61 & 70 & 86 & 91 & 97 \\
\hline Romanía & 40 & 24 & 36 & 20 & 50 & 36 & 74 & 64 \\
\hline Eslovenia & 73 & 68 & 67 & 64 & 85 & 84 & 97 & 95 \\
\hline Eslovaquia & 60 & 69 & 56 & 65 & 74 & 84 & 92 & 90 \\
\hline Finlandia & 77 & 74 & 73 & 70 & 89 & 91 & 94 & 90 \\
\hline Suecia & 78 & 87 & 74 & 85 & 95 & 96 & 100 & 99 \\
\hline Reino Unido & 90 & 80 & 89 & 78 & 92 & 93 & 96 & 98 \\
\hline Noruega & 86 & 97 & 86 & 96 & 88 & 99 & 95 & 100 \\
\hline
\end{tabular}

: non dispoñible. Fonte: http://appsso.eurostat.ec.europa.eu/nui/submitViewTableAction.do (02/04/2015)

Se seguimos esta evolución, a VET divídese en dous grupos: (i) unha VET inicial e a (ii) VET permanente. O primeiro vai dirixido á inclusión daquelas persoas fóra da educación obrigatoria, que, en principio, teñen menos de 25 anos. A VET permanente diríxese ás persoas máis maduras, que abandonaron a educación obrigatoria durante un período máis longo. O seu obxectivo é "rehabilitar" as aptitudes xenéricas destas persoas, 
só que estas aptitudes deben estar relacionadas co mercado de traballo e co desempeño específico das súas funcións. Porén, hai probas de que existe pouca sensibilidade para cos obxectivos da formación permanente, tanto os económicos como os que non o son. De feito, a evidencia subliña que os países que amosan un maior compromiso coa formación permanente da súa poboación son aqueles cunha maior implicación corporativa na formación. Neste senso, os países que revelan as mellores prácticas son Dinamarca, Noruega, Suecia, Finlandia e o Reino Unido. Cabe mencionar que Austria e os Países Baixos tamén amosan cifras elevadas, sobre todo en empresas con máis de 50 traballadores. En canto ao resto dos países, en xeral, a porcentaxe de implicación corporativa na formación é baixa, o cal contradi os desexos de Europa. As cifras amosan que as empresas máis grandes son as que máis se implican na formación, comparadas coas máis pequenas. Esta cuestión debería ser asimilada e considerada nos diferentes países de Europa. De feito, unha política corporativa deste tipo promove o crecemento da empresa a diferentes velocidades, o cal pode ter un impacto significativo no seu rendemento económico. Se se confirma, afecta o poder de negociación das empresas no mercado e, ademais, contribúe a aumentar as diferenzas na distribución dos ingresos, con efectos negativos na cohesión e benestar da poboación. Os datos das puntuacións nos indicadores da VET para 2006 e 2010, ilustrados na Táboa 3, confirman este problema.

Táboa 3: Puntuación nos indicadores da VET para 2006 e 2010

\begin{tabular}{|c|c|c|c|c|c|c|c|c|c|c|c|c|c|c|}
\hline & \multicolumn{13}{|c|}{2006} & 2010 \\
\hline & $\mathrm{PT}$ & $\mathrm{SP}$ & EL & IT & $\mathrm{SE}$ & FI & $\mathrm{EU}$ & PT & $\mathrm{SP}$ & EL & IT & $\mathrm{SE}$ & FI & $\mathrm{EU}$ \\
\hline 1.FPP & 28 & 33 & 14 & 29 & 46 & 39 & 33 & 40 & 48 & nd & 36 & 47 & 40 & 38 \\
\hline $\begin{array}{l}\text { 2. Formación } \\
\text { no traballo }\end{array}$ & 9 & 19 & 4 & 7 & 21 & 16 & 16 & 20 & 20 & nd & 11 & 24 & 12 & 21 \\
\hline 3. Empresas & 44 & 47 & 21 & 32 & 78 & 77 & 60 & 65 & 75 & nd & 56 & 87 & 74 & 66 \\
\hline $\begin{array}{l}\text { 4. Gasto } \\
\text { público }\end{array}$ & nd & nd & nd & nd & 0,8 & 1,1 & 0,7 & nd & nd & nd & nd & 0,9 & 1,3 & 0,7 \\
\hline $\begin{array}{l}\text { 5. Custo de } \\
\text { traballo }\end{array}$ & 0,5 & 0,6 & 0,3 & 0,6 & 0,9 & 0,8 & 0,9 & 0,7 & 0,8 & nd & nd & 0,9 & 0,8 & 0,8 \\
\hline
\end{tabular}

Nota: 1. Empregados que participan en cursos FPP (formación profesional permanente) (\%). 2. Empregados que participan na formación no traballo (\%). 3. Empresas que proporcionan formación (\%). 4. Gasto público adicado á IVET (\% do PIB). 5. Gasto das empresas en cursos de FPP como \% do custo total de traballo. Fonte: http:// www.cedefop.europa.eu/ en/ publications-and-resources/

(obtido o 05/ 05/2015)

Onde:

. Traballadores que participan en cursos de FPP (\%): Número de traballadores que participaron en cursos de FPP patrocinados pola empresa nos últimos 12 meses como porcentaxe de todos os traballadores en todas as empresas da enquisa (Eurostat, CVTS)

. Traballadores que participan na formación no traballo (\%): Número de empregados que participaron na formación no traballo patrocinada polas empresas durante os últimos 12 meses como porcentaxe de todos os traballadores en todas as empresas na enquisa (Eurostat, CVTS). 
- Empresas que proporcionan formación (\%): Porcentaxe de empresas que proporcionaron algún tipo de formación vocacional aos seus traballadores durante os últimos 12 meses (Eurostat, CVTS).

. Gasto público en IVET (\% do PIB): Gasto público na educación vocacional para o nivel de secundaria e superior (ISCED 3 e 4) como porcentaxe do PIB (Eurostat, UOE)

. Gastos da empresa en cursos de FPP como \% do custo total do traballo: gasto en cursos de FPP como \% total do custo de traballo: Gasto Monetario Total (GMT) por empresas con cursos de FPP como \% do total do custo de traballo (todas as empresas). O indicador GMT exclúe os custos da ausencia de persoal (cálculo Cedefop baseado en Eurostat, CVTS)

Segundo os datos ilustrados na Táboa 3, hai unha considerable asimetría entre os países que analizamos (Portugal, España, Grecia, Italia, Suecia e Finlandia). Decidimos presentar estes seis países, agrupados en dous bloques: o bloque dos países do sur de Europa con supostas debilidades estruturais socioeconómicas, e dous países de referencia en Europa, tanto en termos económicos como sociais. Os datos sinalan que hai un comportamento heteroxéneo no grupo de países do sur de Europa. Como se ve, España, seguida de Portugal, presentan indicadores que amosan que se realizaron esforzos no campo da VET e da formación permanente. Aínda así, malia que os datos revelan unha mellora de 2006 a 2010, os traballadores implicados na formación no traballo son poucos nos países do sur de Europa. Cabe sinalar que as nosas descubertas son consistentes cos datos proporcionados (i) polas empresas que proporcionan formación e (ii) polos gastos das empresas en formación, medidos como porcentaxe do gasto total en traballo. Con respecto ao gasto público en IVET, non hai datos dispoñibles para os países do sur de Europa durante os dous anos analizados.

En xeral, os datos son máis expresivos e consistentes nos dous países de referencia, e menos expresivos nos catro menos desenvolvidos e estruturalmente menos equilibrados. Tamén convén destacar que os datos suxiren que hai unha necesidade de analizar máis profundamente os resultados da formación en termos específicos, e os resultados da formación permanente en termos máis xerais. Aínda que os resultados sociais predominan da vida cotián, permitirían medir a eficacia do investimento realizado neste campo. Porén, nesta área sería de máxima importancia que as empresas aumentaran os seus esforzos e investiran máis porque son os primeiros en beneficiarse de traballadores mellor formados e educados. Por tanto, deberíanse deseñar moitas políticas dirixidas ás empresas, que alertaran do seu papel como axentes sociais. As empresas deberían cultivar os valores da cidadanía entre os seus traballadores. As empresas constrúense cunha vocación a longo prazo e non deberían procurar resultados económicos a curto prazo. Por iso, deberían mellorar e actuar na súa estratexia, procurando acadar marcos sostibles dinámicos.

\section{Conclusións}

Hoxe en día somos testemuñas de cambios no xeito en que as organizacións xestionan as súas competencias e aptitudes. Poden proporcionar formación e facer que os seus traballadores sexan conscientes da importancia da formación porque é unha variable estratéxica para as organizacións que desexen manter os seus recursos humanos competentes e coñecedores das últimas tecnoloxías e dos cambios sociais co obxecto de garantir altos niveis de rendemento. A formación permite que a organización poida responder aos retos de como escoitar, como ver, como comunicar e como sentir porque son dimensións estratéxicas na nova economía e esenciais para a capitalización do coñecemento tácito, o cal é un factor produtivo diferenciador para as organizacións. Nembargantes, a formación tamén é un instrumento para a avaliación do coñecemento, por tanto, funciona como unha receita terapéutica para as organizacións con baixos 
redementos e que necesitan adaptarse ás demandas da vida real. En xeral, as competencias emerxen dende dentro das empresas, co nexo entre os recursos e as rutinas. Como competencias centrais nunha sociedade do coñecemento, son dunha natureza fundamentalmente tácita. Por iso, o rendemento das empresas e o desenvolvemento local dependen directamente da súa evolución e, por iso, do tipo de política de incentivos, tanto público como privado.

Convén subliñar que as competencias, especialmente as brandas, teñen un efecto nunha sociedade do coñecemento e diferencian as organizacións e rexións onde están situadas. Por tanto, as organizacións deberían proporcionar formación específica aos seus traballadores e fomentar a súa formación permanente.

A pesar da importancia da aprendizaxe permanente, as empresas, sobre todo as pequenas, non se implican na formación. Como os traballadores adultos non semellan ser conscientes dos beneficios de adquirir novos coñecementos, sobre todo aqueles que abandonan o sistema educativo pronto, faise difícil estimular e actualizar os seus coñecementos, tanto os instrumentais como os técnicos e aqueles de natureza social, relacional e emocional. Baixo estas circunstancias, faise difícil estruturar o rendemento económico e social dos países máis débiles no que se refire á súa estrutura produtiva. Por outra banda, as grandes empresas, conscientes desta realidade e dos valores engadidos que implica a formación, amósanse dispostas a facer realidade este instrumento. Por tanto, identifícanse dúas velocidades para o rendemento económico e corporativo, o cal é daniño para a satisfacción de vida e no traballo. Isto convértese nun foco potencial de diferenzas, que dan orixe a desigualdades e ineficacias, o cal ten un efecto na calidade de vida da poboación.

É por iso que este artigo sinala o perigo da falta de consciencia tanto dos cidadáns como das empresas sobre a importancia da formación permanente. Por tanto, é urxente instituír políticas de incentivo e aumentar a concienciación tanto dos axentes públicos como privados sobre este tema. Apoiamos a necesidade urxente de diseminar este tipo de políticas, sobre todo aos empresarios, os executivos e os corpos técnicos, coa esperanza de que fomenten e estimulen a todos os cidadáns. Do contrario, será difícil redefinir sistemas innovadores eficaces, tanto no sistema a nivel nacional como rexional, local ou sectorial, onde a avaliación da formación é un dos niveis de produción de competencias e sustentabilidade.

\section{References}

Afonso, A. (2000). Avaliação Educacional: Regulação e Emancipação, Cortez Editora.

Bilhim, J. (2006). Gestão Estratégica de Recursos Humanos, Segunda Edição Revista e atualizada, Universidade Técnica de Lisboa, Instituto Superior de Ciências Sociais e Políticas.

Bishop, J. (1998). "Occupation-Specific versus General Education and Training", The ANNALS of American Academy of Political and Social Science, 559: 24-38.

Byers, L. \& Rue, W. (1996). Gestión de Recursos Humanos, Madrid: Mosby-Doyme Libros S.A. División IRWINS.

Cedefop (2008). Terminology of European education and training policy. A selection of 100 key terms. Luxembourg: Office for Official Publications of the European Communities.

Cedefop (2013). Benefits of vocational education and training in Europe for people, organisations and countries. Luxemburg: Publications Office of the European Union.

Cedefop (2014). Macroeconomic benefits of vocational education and training. Luxemburg: Publications Office of the European Union. Reserach Paper no 40. 
Cohen, W. \& Levinthal, D. (1990). “Absorptive capacity: a new perspective on learning and innovation", Administrative Science Quarterly, Vol. 35(1): 129-152.

Contreras Cueva, A. B., Dávalos García, S., González-Morales, O. \& Álvarez-González, J. A. (2014). "The employability of mexican university students: an analysis by gender and training areas". Regional and Sectoral Economic Studies Vol. 14(3); 155-168.

Cruz, J. (1998). Formação Profissional em Portugal: do levantamento de necessidades à avaliação, Lisboa, Edições Sílabo.

Descy, P. \& Tessaring, M. (2001). Formar e aprender para gerar competências, Segundo Relatório sobre Investigação no domínio de Formação Profissional na Europa: Sinopse, Luxemburgo: Serviço de Publicações Oficiais das Comunidades Europeias.

Donovan, P., Hannigan, K. \& Crwe, D. (2001). "The learning transfer system approach to estimating the benefits of training: empirical evidence", Journal of European Industrial Training: 221-228.

European Commission/ EACEA/ Eurydice (2015). Adult Education and Training in Europe: Widening Access to Learning Opportunities. Eurydice Report. Luxembourg.

Fernandes, A. (2007). Tipologia da Aprendizagem Organizacional: Teoria e Estudos. Lisboa, Livros Horizonte.

Gómez, N., Tobarra, M.A. \& López, L. A. (2014). “Employment opportunities in Spain: gender differences by education and ICT usage". Regional and Sectoral Economic Studies Vol. 14(3): 105-130.

Greenan, K., Humphreys, P. \& McIlveen, H. (1997). “Developing transferable personal skills: part of the graduate toolkit", Education +Training, Vol. 39(2): 71-78.

Holton, E.; Bates, R. \& Ruona, W. (2000). “Development of Generalized Learning Transfer Inventory", Human Resource Development Quartely, Vol. 11(4): 333-360.

Holton, E; Bates, R. \& Bookter, A. (2007). "Convergent and Divergent Validity of Learning Transfer Inventory", Human Resource Development Quartely, Vol. 18(3): 385-419.

Kirby, S., Riley, R. (2008). "The external returns to education: UK evidence using repeated cross-sections". Labour economics, Vol. 15(4): 619-630.

Lall, S. (1992). "Technological capabilities and industrialization". World Development, 20(2): 165-186.

Landriscini, G., Preiss, O., Rivero, I. \& Roca, S. (2006/ 07). “Circulación de información y creación de competências en una red frutícola asociativa del Alto Valle de Río Negro Y Neuquén", Revista Pilquen, Sección Agronomía, Año VIII, no 8: 01-20.

Le Clech, N. A. \& Gimenez, G. (2015). "Efectos del capital humano en el sector agrícola: análisis de 12 países de la OCDE”, Regional and Sectoral Economic Studies, Vol. 15(1): 169-186.

Lugones, G. \& Gutti, P. (2006). “Cambio tecnológico en América Latina: Análise del desarrollo de las capacidades tecnológicas en los países de América Latina”, Informe $\mathrm{n}$ ㅇ 4, Segundo Borrador de Informe Final, Noviembre de 2006. Centro Redes.

Lundvall, B.-A. (1985). Product Innovation and User?Producer Interaction. Aalborg: Aalborg University Press.

Lundvall, B.-A. (1988). "Innovation as an interactive process: from user- producer interaction to the national system of innovation" in Dosi, G. Freeman, C., Nelson, R., Silverberg, G. \& Soete, L. (eds.), Technical Change and Economic Theory. London: Pinter Publishers: 349.369.

Lundvall, B.-Å. (2006). Knowledge Management in the Learning Economy, Working paper no 06-6, DRUID-Danish Research Unit for Industrial Dynamics.

Lundvall, B.-A.. (2007). "Higher Education, Innovation and Economic Development”, World Bank's Regional Bank Conference on Development Economics, Beijing. 
Magalhães, A. \& Stoer, S. (2006). Reconfigurações- Educação, Estado e Cultura numa Época de Globalização. Porto, Profedições.

March, J. G. (2006). "Rationality, Foolishness, and Adaptative Intelligence", Strategic Management Journal, Vol. 27(3): 201-214.

Nelson, R. R. \& Winter, S. (1982). An Evolutionary Theory of Economic Change, Harvard University Press.

Nonaka, I. (1991). "The knowledge-Creating Company", Harvard Business Review, November-December: 96-104.

Nisar, T. (2004). "Training as a strategy in value-creation processes". Vocational Training European Journal, nº. 31, Luxemburg - Cedefop: 3-9.

Pereira, O., (1997). A Formação Profissional: o caso português, Tese de Mestrado, Braga, Universidade do Minho.

Pereira, O., (2001). Formação Profissional e Inovação na Indústria Transformadora Portuguesa; análise da estratégia sectorial, Tese de Doutoramento, Universidade de Santiago de Compostela, Espanha.

Pereira, O. (2008). "Educação, competências e habilidades na perspectiva evolucionista". In Neira et al (ed), Investigaciones de Economía de la Educación, número 3. España: AEDE-Asociación de Economía de la Educación: 209-216.

Pereira, O. (2013a). "Soft Skills: From University to Work Environment. A Survey of Graduates In Portugal". Regional and Sectoral Economic Studies, Vol. 13(1): 105118.

Pereira, O. (2013b). "Metacompetences: how important for Organizations? Analysis of a survey in Portugal". Regional and Sectoral Economic Studies, Vol. 13(2): 73-88.

Pereira, O., Martins, A., and Martins, I. (2007). "Learning Organisations and Knowledge Maps: analysis of a Survey in Portugal”. International Journal of Applied Econometrics and Quantitative Studies, Vol. 4(1): 57-81.

Rosegger, G. (1986). The Economics of Production and innovation-An Industrial Perspective, Oxford, Pergamon Press.

Teece, D.J. \& Pisano, G. (1994). "The dynamic capabilities of firms: an introduction", Industrial and Corporate Change, Vol. 3(3): 537-556.

Thang, N.N. et al. (2010). "The relationship between training and firm performance: a literature review". Research and practice in human resource management, Vol. 18(1): 28-45.

Walker, B. (1987). "Training and/ or Education - The new equilibrium", Journal of Vocational Education \& Training, Vol. 39: 19-22.

Wollschlälger, N. (2004). "Da divergência à convergência - Uma história do ensino e formação profissional”, Revista Europeia Formação Profissional, no 32, Luxemburgo, Cedefop.

Decreto-Lei n. 396/ 2007, de 31de Dezembro, Diário da República, 1a Série, no 251: 91659173.

Annex on line at Ideas: http:// https:/ / ideas.repec.org/ s/ sdo/ regaec.html

Rules and News of Revista Galega de Economía at: http:/ / www.usc.es/ econo/ RGE/ benvidag.htm 